\title{
En la cuenta del tiempo. ¿Qué le debe Gadamer a Husserl?
}

\author{
In the time count. \\ What does Gadamer owe to Husserl?
}

\author{
FRANCISCO DÍEZ FISCHER \\ Universidad Católica Argentina, Buenos Aires (Argentina) \\ CONICET
}

Recibido: 08-01-2011 Aprobado definitivamente: 18-05-2011

\section{RESUMEN}

El programa del siguiente estudio es esclarecer la eficacia histórica que la fenomenología de la conciencia del tiempo de Husserl tiene sobre la hermenéutica filosófica de Hans-Georg Gadamer; herencia que Gadamer mismo reconoce cuando afirma «que una clara línea conduce desde el concepto de síntesis pasiva y la teoría de la intencionalidad anónima a la experiencia hermenéutica $[\ldots] »{ }^{1}$

\section{PALABRAS CLAVE \\ FENOMENOLOGÍA, HERMENÉUTICA, CONCIENCIA, TIEMPO.}

\begin{abstract}
The plan of this study is to clarify the historical efficacy of Husserl's phenomenology of time consciousness in the philosophical hermeneutics of Hans-Georg Gadamer. Gadamer himself accepts this legacy when he says that «a clear line leads from the concept of passive synthesis and the theory of anonymous intentionality to the hermeneutic experience $[\ldots] »$.
\end{abstract}

\section{KEYWORDS}

PHENOMENOLOGY, HERMENEUTIC, CONSCIENCE, TIME.

1 Gadamer, H.G., «Entre fenomenología y dialéctica. Intento de autocrítica», Gesammelte Werke 2. Tübingen: Mohr (Paul Siebeck), 1999, p. 16.

(C) Contrastes. Revista Internacional de Filosofía, vol. XVII (2012), pp. 139-157. ISSN: 1136-4076

Departamento de Filosofía, Universidad de Málaga, Facultad de Filosofía y Letras Campus de Teatinos, E-29071 Málaga (España) 
EL ANÁLISIS DE LA CONCIENCIA DEL TIEMPO constituye uno de los temas centrales de la fenomenología que todos sus principales representantes o herederos han abordado en profundidad. Ha tenido un lugar medular en los escritos de Martin Heidegger, Jean-Paul Sartre, Maurice Merleau-Ponty, Paul Ricoeur, Emmanuel Levinas y Jacques Derrida. Hans-Georg Gadamer parece ser la excepción a esta regla en tanto es la única figura descendiente de la fenomenología en cuyos escritos el tema no recibe un tratamiento sostenido. El hecho no deja de ser curioso, pues su hermenéutica filosófica se enraíza fuertemente en la tradición de la fenomenología. ¿Se trata de un simple descuido? o ¿hay una distancia más profunda que dificulta, en este caso, hablar de una herencia eficaz?

Por lo general, la tematización de la temporalidad aparece relacionada con problemáticas referidas a la constitución del objeto y de la conciencia. Dado que todos los objetos aparecen como objetos que duran, debe haber una explicación de cómo el yo constituye la unidad de esa duración. Bajo esta perspectiva, podemos argumentar en favor de Gadamer que, al adherir en parte a la crítica de su maestro Heidegger contra la fundamentación trascendental, tiene derecho a desatender un enfoque de análisis del tiempo desde su constitución egológica última. En su contra, podemos argüir que Heidegger y Merleau-Ponty, aunque rechazan un fundamento trascendental, se ocupan explícitamente de las cuestiones sobre la conciencia del tiempo. ¿Qué sucede, entonces, con Gadamer?

\section{EL CONFLICTO POR LA HERENCIA DE LA FENOMENOLOGÍA}

En el horizonte histórico general de la hermenéutica, la eficacia de la fenomenología husserliana parece tocar de lleno la génesis de sus orígenes filosóficos. Si bien vale decir con Grondin, ${ }^{2}$ que los aportes de Husserl a la hermenéutica se han producido casi a pesar suyo y hasta se le puede considerar un «alérgico» a ella en tanto no toleraba su historicismo (como testimonia su debate con Dilthey de 1911), su rechazo tampoco parece haber sido tan radical ni absoluto. Sin duda, le interesaban más los fenómenos mismos que sus interpretaciones, pero sugiere ya Ricoeur, -tal vez el más fenomenólogo de los hermeneutas-, que el famoso lema «el retorno a las cosas mismas», es decir, a lo esencial que se mantiene a través de las interpretaciones, se realiza precisamente en la multiplicidad de interpretaciones, pues es al hilo de ellas que se termina por reconocer aquello esencial a un fenómeno. De manera que la fórmula de Investigaciones Lógicas «de las meras palabras [...] a las cosas mismas» podría releerse hermenéuticamente. Lo que hay detrás de las palabras no son tanto las cosas, sino las intenciones de sentido que constituyen las cosas, por eso el retorno a ellas es interrogar a la intencionalidad linguística oculta detrás de lo que se muestra, lo cual ya es

$2 C f$. Grondin, J., «La contribution silencieuse de Husserl à l'herméneutique», Philosophiques, $\mathrm{N}^{\circ} 2$ (1993), pp. 383-398. 
una tarea hermenéutica. Claro que no deja de ser irónico que una filosofía que buscaba liberar al pensamiento de las interpretaciones, las teorías y los libros, haya aportado tanto a una corriente filosófica cuya orientación textual es tan pronunciada. Por extraño que sea, Husserl es uno de los principales filósofos al que la hermenéutica hace referencia cuando, preocupada por sus orígenes, rehace idealmente el camino que ha permitido que ella exista.

En el horizonte histórico personal de Gadamer, la fenomenología fue representante de una nueva pretensión de objetividad que llegó a alcanzar el sentido de un mensaje crítico de salvación. «Sin duda, las expectativas con las que, en aquella época, una generación joven se introducía en la disciplina metódica de la escuela fenomenológica, pretendían mucho más que la fundación de la filosofía como ciencia estricta. En una generación en búsqueda fermentaban necesidades no clarificadas de orden religioso, político-social y moral existencial que, con el derrumbe de la cultura de preguerra, ya no podían ser satisfechas y hasta habían perdido toda orientación». ${ }^{3}$ En el comienzo de sus estudios, Gadamer intentó familiarizarse con la fenomenología. Por recomendación de Hartmann asistió en 1921 a las clases de Moritz Geiger y Alexander Pfänder, quienes no le impresionaron por ser sobrios, secos y carentes de demonismo. ${ }^{4}$ Su primer contacto con Husserl fue a través de la lectura de Investigaciones lógicas, publicada el mismo año de su nacimiento (1900). Gadamer leyó sus mil páginas cuando cayó enfermo de poliomielitis en 1922 a modo de preparación de su viaje a Friburgo donde, con la expectativa de ir a estudiar con Heidegger, llegó a conocer y a asistir a las clases de Husserl. En Investigaciones lógicas, éste proponía que todas las filosofías en uso se nutrían de una conceptualización que pasaba de largo de las cosas mismas, incluso cuando hablaban de ellas. De modo que el eje programático de una nueva objetividad debía consistir en un regreso a los fenómenos. En qué medida Husserl cumplía con esta promesa salvadora fue algo que se convirtió en cuestión de debate a partir de las críticas de su discípulo disidente Heidegger que le reprochaba seguir venerando unas conceptualizaciones que tampoco había obtenido a partir de las cosas mismas. La de Husserl no parecía ser una fenomenología suficientemente fenomenológica porque tomaba sus conceptos de una tradición cuyos fundamentos ontológicos había que analizar más a fondo y críticamente. Gadamer seguía en directo el debate entre sus maestros porque allí se estaba jugando algo más que una lucha entre egos demoníacos, se jugaba la perspectiva futura de la filosofía.

3 Gadamer, H.G., «Fritz Kaufmann», GW 10. Tübingen: Mohr (Paul Siebeck), 1999, p. 427.

$4 C f$. Gadamer, H.G., «Die deutsche Philosophie zwischen den beiden Weltkriegen», $G W$ 10, p. 382. 
Él mismo reconoce que, en las lecciones de Husserl de aquella época, aprendió «el arte de la descripción fenomenológica» que más tarde consideraría idóneo para una interpretación de textos orientada hacia las cosas mismas. En las de Heidegger, escuchó las críticas a la fenomenología, pero también aprendió que Husserl no había rechazado tan rotundamente el enfoque hermenéutico al enseñar a ver todos los fenómenos de la conciencia como fenómenos de la intencionalidad, lo cual luego sería considerado como el principio básico de la hermenéutica. El ojo de la tormenta destructora de Heidegger pasaba por aquí: la universalidad de la intencionalidad descubierta por Husserl es incompatible con la fundamentación en el ego trascendental como instancia última y comienzo absoluto. Esto mismo sería confirmado, años más tarde, por Ricoeur al decir que «la fenomenología que era descendiente del descubrimiento del carácter universal de la intencionalidad, no ha seguido el consejo de su propio descubrimiento, a saber que la conciencia tiene su sentido fuera de ella misma». ${ }^{5}$ Fue necesario esperar a Heidegger para que la condición de pertenencia fuese conceptualizada como «el ser en el mundo que precede la reflexión» y por lo mismo presentada como condición ontológica de la comprensión y fundamento de la intencionalidad. Su mérito fue haber mostrado el enraizamiento de la conciencia pensante en eso que ella intenta pensar y haber destacado la dimensión positiva de la finitud como inserción de nuestro ser en los horizontes de sentido que lo exceden. El patrimonio trascendental de la fenomenología había escrito su futuro en dirección a la hermenéutica.

\section{EL INTERÉS ESPECIAL POR LA FENOMENOLOGÍA DEL TIEMPO}

De todo el legado que Gadamer recibió de Husserl pareciera que el tema de la conciencia del tiempo ha sido el menos influyente, pues efectivamente no tuvo un desarrollo explícito y sostenido a lo largo de su extensa obra. Su referencia queda reducida a algunos pasajes como el que aquí recogemos: «La fenomenología de la conciencia del tiempo explica la fundamentación temporal de la validez objetiva. Tal es la indudable intención de Husserl y no deja de ser convincente. La identidad no desaparece, a mi entender, rechazando la idea husserliana de fundamentación trascendental y, con ello, el reconocimiento del ego trascendental y su autoconstitución temporal como última instancia fundamentadora de las Investigaciones lógicas. La identidad del yo y la identidad del sentido que se constituye entre los interlocutores no quedan erosionados por eso». ${ }^{6}$ Gadamer rechaza de la mano de su maestro Heidegger la autoconstitución temporal del

5 Ricoeur, P., Del texto a la acción. Buenos Aires: FCE, 2001, p. 51.

6 Gadamer, H.G., «Entre fenomenología y dialéctica. Intento de una autocrítica», $G W 2$, p. 16 . 
yo trascendental, ${ }^{7}$ pero reconoce la validez que el Husserl tardío otorga a la constitución pasiva de la identidad del yo y del sentido, aunque «es cierto que la compresión de uno por otro no cubre todo el ámbito de lo comprendido». ${ }^{8}$ La excedencia del horizonte impide que el modelo de la comprensión pueda ser entendido como un acuerdo en el que la diferencia se disuelve en la identidad. Uno no se identifica con la opinión del otro. En la comprensión hermenéutica hay más bien una co-incidencia que mantiene siempre la diferencia, pues se da en el horizonte último de la pertenencia al lenguaje como diálogo. Gadamer observa que Husserl ya aclaró esto: «Creo que del concepto de síntesis pasiva y de la doctrina de las intencionalidades anónimas hay una clara línea que llega a la experiencia hermenéutica y que podría coincidir, siempre que se rechace la violencia metodológica del pensamiento trascendental, con mi fórmula «cuando se comprende, se comprende de un modo diferente». ${ }^{9}$ ¿A qué clase de «clara línea» se refiere Gadamer aquí? ¿Hay en su intento de autocrítica un reconocimiento de la coincidencia con el proyecto fenomenológico? o ¿se trata más bien de subsanar un descuido en agradecimiento al maestro?

\section{LA EVOLUCIÓN DE LA TEORÍA FENOMENOLÓGICA DE LA CONCIENCIA DEL TIEMPO}

Para tratar de entender por qué Gadamer reconoce una trayectoria concurrente tan expresa, consideremos la evolución de los estudios de Husserl. En su desarrollo del problema de la conciencia del tiempo pueden distinguirse tres períodos: 1) desde las lecciones de 1904 y 1905 hasta Ideas $\left.I(1913) ;{ }^{10} 2\right)$ los manuscritos de Bernau de 1917 y 1918, ${ }^{11}$ y 3) los manuscritos C de 1929 a $1934 .{ }^{12}$ El punto de partida de las lecciones de $1904 / 5$ es, precisamente, el

7 Respecto de la discusión entre Husserl y Heidegger en torno a la conciencia del tiempo, Husserl mismo señala que encuentra «literalmente casi ilegibles» sus propias reflexiones tal como han sido editadas por Heidegger. $C f$. Husserl, E., Briefwechsel. Dordrecht: Kluwer, 1993, V. 5 , p. 186.

8 Gadamer, H.G., «Entre fenomenología y dialéctica. Intento de una autocrítica», $G W 2$, p. 16.

9 Ibid.

10 Husserl, E., Zur Phänomenologie des inneren Zeitbewusstseins (1893-1917), Husserliana X. Den Haag: Martinus Nijhoff, 1966 e Ideen zu einer reinen Phänomenologie und phänomenologischen Philosophie, Band I, Husserliana III. Lovaina, 1950.

11 Husserl, E., Die ,Bernauer Manuskripte “ über das Zeitbewußtsein (1917/18). Edited by Rudolf Bernet \& Dieter Lohmar. Dordrecht, Netherlands: Kluwer Academic Publishers, 2001.

12 Husserl, E., Späte Texte über Zeitkonstitution (1929-1934), Die C-Manuskripte, Husserliana Materialien. Tomo 8, Dordrecht: Springer, 2006. Seguimos aquí el Seminario del Dr. Roberto Walton, dictado en el 1er semestre de 2008 en la Facultad de Filosofía y Letras de la Universidad de Buenos Aires: Presente viviente, mundo y latencia en los manuscritos tardios de E. Husserl sobre el tiempo, y el artículo de Conde Soto, F., «Importancia y evolución del concepto de conciencia del tiempo en la fenomenología de Edmund Husserl», Contrastes, Vol. 
estudio de cómo es posible la percepción de los objetos que duran. Los análisis conducen a través de la intencionalidad de los actos constitutivos (percepción, recuerdo, fantasía, conciencia de imagen) hacia la estructura de la conciencia constituidora de la síntesis que combina las fases presentes, pasadas y futuras para que podamos percibir la unidad del objeto que dura. Husserl introduce una estructura formada por tres elementos: protoimpresión, retensión y protensión, que son las partes del acto perceptivo, por las cuales los datos se presentan a la conciencia inmanente. A partir de esos datos es posible explicar la constitución del tiempo objetivo, pero aún no son ellos mismos unidades propiamente temporales. El tiempo surge de la objetivación de las vivencias de la conciencia, al ser convertidas en objetos individuales dotados de una posición temporal, por eso uno de los rasgos que caracteriza a esta primera fenomenología del tiempo es su no asunción de un tiempo objetivo-lineal.

Las lecciones del semestre de invierno de 1906/7 constituyen una corrección y complemento de esta teoría e inauguran un segundo momento en la fenomenología del tiempo que se consolida con los manuscritos de Bernau redactados entre 1917 y 1918. «El tema más importante de esos manuscritos es aclarar si la conciencia es una conciencia intencional tempoconstituidora en todo momento y por sí mismo o si por el contrario sus objetos son captados como el resultado de una constitución intencional únicamente cuando el yo se dirige atentamente a ellos, de forma que él activaría así una serie de síntesis previas no intencionales». ${ }^{13}$ Los aportes que aquí interesan para nuestro estudio son tres: (1) la incorporación de la perspectiva afectiva en el análisis del tiempo, que va de la mano (2) del proceso de asociación originaria pasiva previo al operar del yo. El análisis genético trata sobre el destacarse de unidades hyléticas antes de la intervención del yo. Éstas ejercen una fuerza afectante sobre él en vistas a ser captadas. Por eso los datos de la sensación «ya no serán meros datos que aparecen a la conciencia sin más, sino que proceden de una constitución anterior que se produce de forma pasiva antes de toda captación (activa) por parte del yo». ${ }^{14}$ Finalmente, (3) la esfera de la subjetividad trascendental se amplia más allá del yo hacia un proto-yo o vida protofluyente que se corresponde con esos procesos de constitución pasiva.

Desde el extremo opuesto a Heidegger, la crítica de los fenomenólogos más ortodoxos califican estos giros de la fenomenología del tiempo no ya de «insuficientemente fenomenológicos» sino de «explícitamente metafísicos». ${ }^{15}$

XV (2010), pp. 105-123.

13 Ibid., p. 113.

14 Ibid., p. 115.

$15 C f$. Depraz, N., «Temporalité et affection dans les manuscrits tardifs sur la temporalité (1929-1935) de Husserl», Alter 2 (1994), pp. 63-85. Bajo este criterio veremos que lo queda por 
En la medida que la constitución termina por depender de una intencionalidad pasiva, es decir, de un hecho ajeno al yo, que éste no puede justificar, entramos en el terreno de las suposiciones y construcciones metafísicas. Sin embargo, como observan Walton y Conde Soto, la oposición actividad-pasividad no es para Husserl una oposición entre algo propio de la conciencia y algo totalmente ajeno a ella. Las síntesis pasivas y su poder afectante, aunque previos al yo, están dirigidos a despertar una captación en él. Así se inaugura, a través de las nociones de proto-yo y presente viviente, la tercera etapa en los análisis del tiempo.

\section{LAS INVESTIGACIONES TARDÍAS SOBRE LA CONCIENCIA DEL TIEMPO}

Los manuscritos $\mathrm{C}$ fueron editados en 2006 y constituyen un grupo de trabajos de investigación que profundizan la línea del análisis genético. El planteo general de Husserl es que la reducción trascendental no debe detenerse en la puesta entre paréntesis del mundo a fin de reencontrarlo como fenómeno en su correlación con las operaciones de la conciencia, sino que debe extenderse a la vida trascendental a fin de ver en ella el resultado de la temporalización efectuada por el presente viviente que se enlaza con un proto-yo y una protovida trascendental. En este marco, hay tres ideas que destacar en vistas a la eficacia histórica de esta fenomenología tardía del tiempo.

\section{IV.1. PRESENTE VIVIENTE Y PROTO-YO: EL OPERAR ANÓNIMO DE LAS SÍNTESIS PASIVAS}

La radicalización de la reducción conduce del presente perceptivo al presente viviente, nunc stans (ahora estando) o prepresente (Vorgegenwart), que es el movimiento anterior a la entrada en el tiempo inmanente. Husserl lo llama también presente permanente porque es el centro permanente de constitución del curso de las vivencias y del mundo en tanto subsiste como lugar o instancia constante de presentación y se distingue de los presentes inherentes a los actos y a las afecciones que surgen y se desvanecen en el pasado. El término presente le corresponde en tanto es pura actualidad, pero no porque tenga una duración. Sin embargo, su permanencia no excluye un carácter fluyente, pues confluye con los actos del yo que lo presuponen y se constituyen en él. Este movimiento de temporalización o de síntesis universal es la estructura anónima que opera, trabaja y temporaliza de forma continua. Constituye la esfera más originaria en la cual se fundan y generan otros tiempos: la temporalización yoica propia, de los otros yo, el tiempo intersubjetivo, etc. La distinción es correlativa a la de yo y proto-yo: por un lado, el presente permanente o viviente que se diferencia

decir de Gadamer también sería posible de ser calificado de hermenéutica metafísica, tal como han hecho algunos de sus críticos. $C f$. Vattimo, G., Au-delà de l'interprétation. La signification de l'herméneutique pour la philosophie. Paris: éd. De Boeck, 1997, e «Historia de una coma. Gadamer y el sentido del ser», Endoxa: Series Filosóficas, № 20, (2005), pp. 45-62. 
de los presentes que pasan y se hunden en el pasado; por otro, el yo que opera en los actos y afecciones que se efectúan en la originariedad de ese presente viviente y el yo que se encuentra en el presente constituido como un estar-frente intencional. De manera que en el curso de vivencias pueden distinguirse un nivel óntico y otro preóntico, que se entrecruzan, a su vez, con la distinción de un lado noemático, extraño al yo (pero no ajeno a él), es decir, el lado del destacarse de un contenido hylético que afecta y, un lado noético o yoico, que es el polo de unidad que pasa a través de él como estrato constante en el curso de la vida. En el nivel óntico, ambos lados se hallan separados. Allí el ego aparece como yo maduro, centro de la intencionalidad, que se vuelve activamente al mundo con actos que se apoyan en una sedimentación de experiencias pasadas (historia subjetiva). Pero esta separación se sustenta sobre la bilateralidad del nivel previo, donde hay una inseparabilidad de los dos fundamentos primigenios en el fluir originario. Como basamento de la correlación yo-acto-objeto está la correlación protoyo-afección-hyle que se superpone, a su vez, a la indiferenciación preyo-cuasi mundo hylético. Este retroceso a la primigeneidad puede darse como génesis histórica o como génesis viviente. En el primer caso, tenemos un retroceso a la historia pasada del ego y alcanzamos la primigeneidad de quien indaga retrospectivamente a partir del mundo constituido (el ego maduro que medita sobre sí). En el segundo caso, es el retroceso que tiene lugar en cada presente porque un flujo indiferenciado subyace a los datos hyléticos y a los actos que emergen dentro de él. Esta indagación conduce hasta lo que es previo al ser, lo pre-yoico. Permite ir del yo como centro de irradiación de actos al yo como centro de incidencia de afecciones; del yo temático al yo operante (protoyo), y así poner en evidencia que la actividad presupone siempre la pasividad de la afección tanto si se trata de una afección por el estrato hylético o por los actos.

\section{IV.2. PRECEDENCIA Y GRADUALIDAD DE LA AFECCIÓN}

La intencionalidad pasiva temporalizadora operante antes del yo, en tanto es la encargada de la temporalidad de la unidad de las vivencias antes de los procesos de captación, no es para Husserl propiamente intencionalidad ni ejerce ninguna constitución. El término intencionalidad debe reservarse para los actos del yo que son constitutivos e introducen la temporalidad. Previamente solo se puede hablar de una serie de pre-unidades o pre-entes constituidos pasivamente que necesitan afectar al yo para convertirse en objetos, es decir, en unidades temporales. Sin embargo, negarle el carácter de intencionalidad no significa negar que existen procesos genéticos previos, es decir, operaciones anteriores al yo a través de las cuales se forma una unidad que lo puede afectar. En los Análisis sobre la síntesis pasiva (1918/26), Husserl ya define la afección como «el estímulo perteneciente a la conciencia, la particular atracción que un objeto 
consciente ejerce sobre el yo -es una atracción que se distiende en el volversehacia del yo y a partir de ahí se continúa en la aspiración a la intuición que da en sí mismo y que desvela de más en más la mismidad del objeto, esto es, a la toma de conocimiento, a la contemplación más precisa del objeto». ${ }^{16}$ En tanto estímulo la afección es una tendencia (y en tanto tendencia es activa) que se constituye, del lado hylético, como el acometer al yo, la atracción que lo dado ejerce sobre el yo y, del lado yoico, como una tendencia pasiva a ser afectado, la tendencia a abandonarse, a ser-atraído del yo (de modo que afectar al yo es incentivar en él un ser afectado). La afección es pasiva en tanto precede al cogito, pero tiene carácter llamativo porque es una pasividad que motiva la actividad intencional. El yo se vuelve-hacia aquello que lo afecta al punto que el operar intencional se convierte en la resultante de la tendencia afectante. El obrar y el padecer en tanto ser afectado se evidencian así inseparables. La afección como pasividad que pone en movimiento «desempeña ya en la constitución de todas las objetividades su papel esencial, de modo que sin ella no habría objetos y un presente articulado». ${ }^{17}$ Eso quiere decir que el mundo predado es quien hace nacer en el yo una tendencia a ser afectado que le invita a su vez a constituir el mundo, es decir, a hacerlo manifestarse: «Todo objeto constituido es pre-dado en tanto ejerce un estímulo afectante, y dado en tanto que el yo ha respondido a esta estimulación y se ha vuelto hacia él [...]». ${ }^{18}$ En su predación (dación previa implícita y pasiva) el objeto motiva su propia constitución al interpelar y convocar al yo para que responda a su llamado (despertando así su dación explícita y activa). El mundo y los objetos exigen que nos volvamos hacia ellos a fin de darles un sentido que, a la vez, ya está de alguna manera en ellos. Pues el dato de sensación que afecta al sujeto no puede ser una materia muerta sino que ya tiene un sentido en sí mismo, de lo contrario, no podría despertar el interés del sujeto ni motivar su acción. El yo no hace más que responder a un mundo predado ya constituido en la pura pasividad. No produce el sentido, sino que éste es obra de las síntesis pasivas. Claro que tampoco hay sentidos disponibles en sí sin el sujeto. En la forma de un pre-yo o «antecámara del yo», como también lo denomina Husserl, el yo siempre está presente aunque su participación sea pasiva en tanto ser afectado. Eso le revela su condición de pertenencia originaria, pues, antes de oponerse al mundo en una intención objetivante que genera la escisión sujeto-objeto, él mismo pertenece y participa del mundo como uno de sus interlocutores.

16 Husserl, E., Analysen zur passiven Synthesis. Aus Vorlesung- und Forschungs-manuskripten (1918-1926), Husserliana XI. Den Haag: Martinus Nijhoff, 1966, p. 148 ss.

17 Ниа XI, p. 164.

18 Ниа XI, p. 162. 
Al mismo tiempo, la afección exhibe una gradualidad que se sigue de que en la esfera de la pasividad los elementos destacados tienen «diferente fuerza de afección». ${ }^{19}$ Si todo lo que se destaca, también fuera a su vez afectante, el yo se enfrentaría constantemente a innumerables elementos que lo estimularían al punto de no poder responder, es decir, de no poder volverse hacia todo aquello que lo afecta. Además, si lo que no afecta al yo en un determinado presente puede llegar a ser afectante en circunstancias favorables, al igual que lo que le afecta ahora puede dejar de estimularlo, - y suponiendo que una pura nada no puede convertirse en un elemento afectante-, Husserl deduce con razón que lo que no afecta ahora al yo no puede ser totalmente ajeno a la afección sino que debe poseer ya una tendencia hacia ella. Así distingue la afección efectiva y la tendencia a la afección que es la potencialidad de afectar enraizada en la situación hylética global que emite rayos débiles que aún no alcanzan a atraer al yo. De manera que el horizonte se estructura primeramente como un trasfondo en el modo de una «noche silenciosa» que no contiene ningún llamado pero de donde pueden brotar «voces» si aumenta la fuerza de sus componentes, es decir, si llega a destacarse y convertirse en un llamado para el yo. El contraste se convierte en un «fenómeno originario ${ }^{20}$ donde lo explícito llega a ser desde lo implícito, lo cual representa una idea fenomenológicamente tardía, muy cara a la hermenéutica: ya no hay un comienzo absoluto porque todo comienzo se destaca sobre el trasfondo de un pre-comienzo.

\section{IV.3. LA PREDACIÓN DEL YO Y LOS LÍMITES DE LA REFLEXIÓN}

Vivir es ser afectado y, por tanto, un estar fuera de sí que es a la vez condición de acceso al mundo y a sí mismo. El yo no comienza la apertura al mundo ni la apertura a sí. Que la afección se preceda siempre a sí misma, significa que incluso yo me vuelvo en el acto hacia lo que yo ya era en tanto predado. La afección se convierte en condición de posibilidad de la subjetividad y de la identidad no sólo del sentido, sino también del yo. Sin la evocación que proviene del lado no-yoico, no habría subjetividad en sentido estricto. El yo se desvanecería con el curso de sus vivencias porque sería incapaz de identificarse como la identidad que es. A través de las unidades sintéticas que le afectan, se descubre como un polo subjetivo que reacciona ante tales unidades pasivamente predadas. Se revela la actividad inherente a la pasividad misma en las capas constitutivas inferiores pre-yoicas al punto que me soy predado a mí mismo en tanto unidad gracias a estas evocaciones pasivas. Ellas le aseguran a la subjetividad una unidad implícita más acá de la unidad reflexiva y explícita del polo yoico.

19 Husserl E.Zur Phänomenologie der Intersubjektivität. II: 1921-1928, Husserliana XIV. Den Haag: Martinus Nijhoff, 1973, p. 54.

20 Hиа XI, p. 138. 
Tal profundidad en la precedencia de la afección supone, como hemos visto, que la reflexión detecta en el operar del presente viviente algo que no sólo la antecede, sino que supone un operar constitutivo de todo sentido que ocurre primeramente de forma anónima. Incluso cuando la reflexión misma está siendo efectuada esa estructura permanece inaccesible. La reflexión solo es posible como una «captación retrospectiva» o un «percatarse con posterioridad», pues solo se puede reflexionar sobre el yo tal como era hace un momento. El yo operante siempre se encuentra antes de la mirada reflexiva que dirige sobre sí, y en tanto la opera, permanece siempre anónimo. Por el contrario, el yo tematizado por la reflexión ya no opera y se asocia con un presente que se ha convertido en pasado, es decir, sobre el que es posible volver la mirada. De manera que la reflexión introduce esta escisión entre el yo objetivado o tematizado por ella y el yo objetivante y operante (proto yo) y muestra su condición derivada, en el sentido de no-original, porque el yo operante siempre precede al yo tematizado en la reflexión (aunque también la actividad directa del yo operante es derivada en tanto está precedida por la pasividad de la afección). Así el yo como polo idéntico a partir de la pasividad ya es una unidad que pasa a través de todo el curso de la vida y sin embargo no es una vivencia, pues esa unidad es en el anonimato fruto de síntesis pasivas. Recién por la reiterabilidad de la reflexión accedo a la conciencia de su permanencia en el presente.

La reflexión pone en evidencia también que los actos del yo pueden ser afectantes. Una acción, que ha sido motivada por una afección, procede del ego y se dirige a la unidad objetiva. Luego el yo toma conciencia de sí como centro de irradiación de actos e incidencia de afecciones, y esas acciones pueden convertirse, a su vez, en autoafecciones, lo cual requiere que el ego abandone su orientación directa y se vuelva hacia sí mismo en un acto de reflexión. Según Husserl, el yo es incesantemente afectado por sí mismo, de manera que siempre es posible una reflexión del yo que responda al estímulo o interpelación ejercida por los actos. Sin embargo, las autoafecciones no siempre tienen que ser efectivas y motivar el volverse-hacia del yo. De modo que el yo que es activo en la orientación directa puede permanecer anónimo para sí mismo, por ejemplo, en el caso de los actos pasados que sedimentan y nos afectan formando nuestra propia historia efectual según la fórmula de Gadamer.

A causa de los análisis genéticos que descubren esa dimensión anónima y silenciosamente operante que precede a toda reflexión, los críticos consideran que los manuscritos $\mathrm{C}$ llevan a la fenomenología trascendental hasta sus propios límites. «Husserl descubre que ciertos fenómenos nucleares sobre los que se levanta la fenomenología van más allá de lo fenomenológico»». ${ }^{21}$ En la pasividad afectiva, la propia reflexión se topa con su frontera última. Lo cual permite

21 Conde Soto, F., op. cit., p. 121. 
entender por qué los fenomenólogos más ortodoxos consideran que, de la mano de los análisis de la conciencia del tiempo, Husserl termina por abandonar los ideales fenomenológicos y extiende un verdadero cáncer a todo el programa de la fenomenología. ${ }^{22}$ De la vereda contraria, y en vistas a la eficacia histórica que ha tenido, puede verse en estos análisis del tiempo una evolución del pensamiento de Husserl hacia la liberación de la «violencia metodológica trascendental» a través de la extensión de la reducción misma que permite alcanzar el reconocimiento de la positividad de los límites en la propia capacidad reflexiva de la conciencia. Algo que tanto Heidegger, Gadamer y Ricoeur anhelaban ver y no creían concretado en la conciencia autotemporalizante de la primera etapa de la fenomenología.

\section{V. ¿HAY UNA CONTRIBUCIÓN SILENCIOSA DE LA TEORÍA FENOMENOLÓGICA DE LA CONCIENCIA DEL TIEMPO?}

Tal vez ahora se presenta más visible esa «clara línea» que Gadamer tendía desde el concepto de síntesis pasiva y de las intencionalidades anónimas hacia la experiencia hermenéutica. En ese trayecto, los manuscritos de Bernau y del grupo $\mathrm{C}$ constituyen un valioso complemento a la herencia de juventud que Gadamer recibió a través de la lectura de Ideas I e Investigaciones Lógicas. En el semestre de verano de 1923 cuando asiste a las lecciones de Husserl, si bien versaron sobre Lógica Trascendental, éste ya se encontraba en plena reelaboración de los análisis de la conciencia del tiempo en una dirección coincidente con las críticas de la hermenéutica. ¿Qué ocurrió entonces? ¿Puede pensarse que estas investigaciones fenomenológicas en plena ebullición hayan sido una influencia oculta y silenciosa para Gadamer? Sabemos que éste no realiza un desarrollo explícito de la problemática de la conciencia del tiempo pero, en vistas a su reconocimiento de la línea de coincidencia con el Husserl tardío, hay dos elementos que destacar. 1) Si bien Gadamer no trata explícitamente el problema del tiempo, todos sus temas ya están de alguna manera atravesados por esta problemática: la conciencia de la eficacia histórica del pasado, la temporalidad de lo estético, la noción de fiesta, la simultaneidad temporal como tarea de actualización, las elaboraciones en torno al tiempo vacío y al tiempo lleno son ejemplos de una tematización implícita aunque en nada periférica. 2) Así como la fenomenología del tiempo tiene una posición estratégica en la evolución del pensamiento de Husserl, es reconocida y extendida la idea que,

22 Wälde afirma que no sólo la fenomenología del tiempo es un proyecto destinado desde el principio al fracaso sino que en su fracasar se lleva por delante también la validez de toda la fenomenología. Cf. Wälde, M., Husserl und Schapp: Von der Phänomenologie des inneren Zeitbewusstseins zur Philosophie der Geschichte. Basel: Schwabe and Co., 1985, p. 91 ss. y Conde Soto, F., op. cit., pp. 121-122. 
en la hermenéutica filosófica, los análisis estéticos ofician de paradigma de comprensión en el examen de la experiencia. Los temas del tiempo y de su conciencia no son la excepción en tanto, reiteradas veces, son abordados por Gadamer desde la perspectiva de la temporalidad del arte. Pero ¿puede extraerse de aquí una teoría hermenéutica de la conciencia del fluir temporal? Sin duda, si existiera algo parecido, no sería reconocible desde el enfoque de aquella primera fenomenología en tanto la conciencia hermenéutica es una conciencia originariamente perteneciente y participante, $\mathrm{y}$, por lo tanto, extraña a cualquier proceso de autotemporalización.

En vistas a las reelaboraciones del propio Husserl, podemos redimensionar la pregunta y cuestionar ihasta qué punto en las temáticas de Gadamer, incluso en aquellas implícitas sobre el tiempo, hay una influencia de las ideas husserlianas de los manuscritos de Bernau y del grupo C? Tal influjo podría plantearse bajo el supuesto hermenéutico de que la profundidad y la fuerza constituyente de cualquier influencia histórica no está completamente al alcance de la conciencia reflexiva. Por lo cual es legítimo sostener que, de haber aquí una contribución oculta y silenciosa, ésta iría incluso más allá de lo que la hermenéutica puede llegar a saber de sí misma. Si seguimos la línea del análisis genético trazada por la teoría de la síntesis pasiva y de las intencionalidades anónimas, la convergencia parece darse en torno a tres núcleos temáticos principales.

\section{V.1 LA CONDICIÓN DE PERTENENCIA DE LA CONCIENCIA $Y$ LA PRECEDENCIA DE LA PASIVIDAD}

Husserl ha mostrado que la afección en tanto tendencia pasiva a ser-afectado le revela al yo que, antes de oponerse al mundo en una intención objetivante, él pertenece y participa del mundo aunque su participación sea originariamente pasiva. En el programa hermenéutico hay dos ideas enteramente convergentes: 1) la pertenencia originaria de la conciencia y 2) la pasividad precedente que se revela en la negatividad de la experiencia hermenéutica. En ella se encuentra siempre «algo parecido a una dialéctica, un hacer de la cosa misma, un hacer que a diferencia de la metodología de la ciencia moderna es un padecer, un comprender, un acontecer» ${ }^{23}$ En sentido estricto, para Gadamer, una experiencia se tiene, más que se hace, precisamente porque tiene lugar anónimamente «como un acontecer del que nadie es dueño». ${ }^{24}$ La correspondiente condición de pertenencia originaria de la conciencia es el hilo conductor a lo largo de las tres esferas de experiencia hermenéutica (estética, histórica y lingüística) que componen la estructura más profunda de Verdad y Método.

23 Gadamer, H.G., GW 1, p. 469.

24 Ibid., p. 358. 
En la esfera estética, la experiencia de ser atraído por el juego de la obra, siempre precede y hace posible el ejercicio del juicio crítico de la conciencia estética. A través de la intencionalidad lúdica, el verse-vuelto-hacia queda determinado por un previo verse-envuelto-por el juego que mantiene la precedencia de la pasividad. El obrar y el padecer, -éste ahora entendido en la positividad de ser-tentado- $a-$, se evidencian también aquí como inseparables. El valor del concepto de juego es dar a pensar un nuevo modo de intencionalidad que no sea enfrente-a, pues la obra de arte no es ningún objeto frente-al-cual se encuentre un yo que lo es para sí mismo; y eso coincide con la espontaneidad de la puesta entre paréntesis de su realidad. ${ }^{25}$ La participación lúdica tiene el carácter de un estar fuera de sí que, en la fenomenología, es condición de acceso a sí mismo y al mundo, del mismo modo que lo es en la hermenéutica, en tanto posibilidad positiva de asistir a algo por entero. La pasividad de ser afectado alcanza en la asistencia un estar fuera de sí como auto-olvido que «no tiene aquí nada que ver con un estado privativo, pues su origen está en el volverse hacia la cosa, y el espectador lo realiza como su propia acción positiva». ${ }^{26}$

En la esfera histórica, la influencia toca de lleno una temática temporal muy concreta. La conciencia de ser sostenido por tradiciones que nos preceden y a las que pertenecemos, hace posible todo ejercicio de una metodología histórica en el nivel de las ciencias del espíritu. La noción hermenéutica de tradición indica que nos encontramos inmersos en un proceso temporal sin saber muy bien cómo, y solo en la reflexión nos percatamos, hasta cierto punto, de lo que sucede allí con nosotros. Gadamer formuló esta tesis de una forma provocadora: «En realidad, la historia no nos pertenece, sino que nosotros pertenecemos a ella». ${ }^{27}$ En virtud de esa pertenencia originaria, la conciencia es afectada por el pasado a tal punto que la historia actúa incluso allá donde no se sospecha que lo está haciendo. El término Wirkungsgeschichte refiere a esta eficacia constituyente de las síntesis pasivas. La fuerza de afección del trabajo silencioso del tiempo histórico se asemeja a un trasfondo afectante que ejerce su eficacia por encima de la conciencia (del volverse-hacia) de los individuos que participan de él. En este sentido, la conciencia del tiempo de la fenomenología, en tanto conciencia despertada por la pasividad afectante del mundo predado al que pertenecemos y en el que participamos, tiene su continuidad en la conciencia hermenéutica de

25 Gadamer dice: «En mi opinión, Husserl dio una buena pista de cómo se lleva a cabo la suspensión (Aufhebung) de las expectativas de realidad en el caso de la obra de arte, sin que tengan que entrar en juego las inadecuadas categorías de ficción, ilusión, etc. Él solía observar, en el contexto de la doctrina de la reducción eidética, que ésta, en el caso de la obra de arte, era cumplida 'espontáneamente'.» Gadamer,H.G., «Filosofía y Literatura», GW 8. Tübingen: Mohr (Paul Siebeck), 1999, p. 255.

26 Gadamer, H.G., GW 1, p. 129.

27 Ibid., p. 281. 
la eficacia del tiempo histórico que presupone la inseparabilidad de los polos en el fluir originario y la potencialidad afectante de los trasfondos.

En continuidad con los análisis de la génesis histórica, puede decirse que si yo sé que ha actuado en mí la historia, es decir, que me ha afectado, aunque por la reflexión se me escape siempre el alcance total de la fuerza implícita de su acción, alcanzaré a comprender el carácter constituyente de su eficacia, es decir, de lo que yo ya soy en tanto pre-dado y, por lo tanto, los límites de mi conciencia y de la reflexión tematizante sobre el pasado. En el alcanzarse reflexivo, el yo se comprende como la excedencia de lo que ya es: «somos mucho más, y somos algo diferente, de lo que sabemos nosotros mismos, y que eso que tan ampliamente nos excede a nosotros y a nuestro saber es precisamente nuestro ser más propio». ${ }^{28}$ Cualquier conciencia objetivante que no tenga esto en cuenta llegará siempre demasiado tarde para comprender la experiencia del tiempo.

Finalmente, en la esfera lingüística, que en cierto modo atraviesa las dos anteriores, la experiencia de radical pertenencia al lenguaje como un proto-diálogo siempre ya comenzado e interminable con lo dicho por las voces históricas y por las cosas mismas, hace posible un uso instrumental del lenguaje y una dominación de las estructuras textuales de la cultura. La más fundamental potencialidad lingüística es el previo quedar abarcado todo ente por su posibilidad de venir a la palabra y, por tanto, al mundo, proponiendo un diálogo que siempre nos precede. En virtud de esta fenomenalidad lingüística del ser, podría indicarse un giro fenomenológico en la noción hermenéutica de lenguaje que complementa la universalidad de la intencionalidad y su elevación al mundo intersubjetivo dentro de una praxis comunicativa. "Ahora estamos en condiciones de comprender que este giro del hacer de la cosa misma, del acceso del sentido al lenguaje, apunta a una estructura universal-ontológica, a la constitución fundamental de todo aquello hacia lo que puede volverse la comprensión». ${ }^{29}$ La pertenencia del yo a aquello que lo afecta se manifiesta en la condición de nuestro lenguaje como ser parte de y estar llamado a responder al lenguaje de las cosas mismas; formulación hermenéutica que ahora podemos dar al lema fenomenológico.

\section{V.2. EL CARÁCTER LLAMATIVO DE LA AFECCIÓN Y LA LÓGICA DE PREGUNTA-RESPUESTA}

En los análisis de Husserl, la afección que precede al cogito tiene un carácter llamativo que, del lado noemático, se manifiesta como voz activa interpelante y, del lado noético, como voz pasiva de un llamado a ser-afectado. La afección

28 Gadamer, H.G., «Imagen y gesto», $G W$ 8, p. 327.

29 Gadamer, H.G., GW 1, p. 478. 
se destaca sobre el trasfondo de lo advertible (de lo que precisamente aún no se abre paso con su voz) motivando la actividad del yo de volverse-hacia aquello que lo afecta. En cierta medida, el carácter llamativo y pro-vocador de la afección ya ha aparecido en las esferas de la experiencia hermenéutica. Por un lado, la determinación hermenéutica del ser como ser-voz, es decir, de la voz histórica de las cosas mismas en tanto fuerza afectante en el ahora presente, indica que el pasado de la tradición no es verdaderamente pasado, sino que permanece siempre presente y operante como afección interpelante. Por otro lado, la experiencia de pertenencia a un proto-diálogo que nos precede se estructura bajo la lógica de una pregunta motivante y una intencionalidad responsiva. El carácter llamativo está presente en el círculo hermenéutico como motivación desde el lado no yoico en el modo de una afección interrogante de aquello a lo que el comprender pertenece (una respuesta pertenece a una determinada pregunta que la genera). En su precedencia se aproxima a la doble dimensión activo-pasiva de la afección: 1) porque «el preguntar es más un padecer que un hacer», ${ }^{30}$ la pregunta se impone y quien la escucha acepta una intromisión que acomete al yo desde un lado no yoico; 2) porque la pregunta comparte la pasividad de la afección en tanto el ser-interrogado es siempre precedente y su pasividad tiene un doble sentido negativo-positivo. La negatividad hermenéutica más radical de esta afección es el «saber que no se sabe» que es la conciencia de finitud y de pertenencia en tanto condición precomenzada de la comprensión. Su sentido positivo radica en que preguntar como ser interrogado quiere decir abrir al asi $o$ de otro modo. Esa es la forma hermenéutica del volverse-hacia que despierta la afección de la pregunta. No obstante, la positividad de la apertura implica sus límites, pues «en ella está contenida una delimitación implicada por el horizonte de la pregunta». ${ }^{31}$ Del mismo modo que una afección presupone un trasfondo afectante, el planteamiento de una pregunta implica una apertura limitada que es el sentido pre-dado que trae la pregunta como sentido de orientación, es decir, el «así o también de otras ciertas maneras» que puede adoptar la respuesta si quiere ser adecuada.

\section{V.3. EL PRESENTE VIVIENTE Y LA TEMPORALIDAD FESTIVA}

Bajo el arquetipo hermenéutico de la experiencia del arte y en continuidad con los análisis de la génesis viviente, se puede trazar una convergencia final entre el presente viviente y la temporalidad festiva; dos nociones temporales que son centrales en la fenomenología tardía y en la hermenéutica. Para Gadamer todo ser es como la obra de arte un «presente absoluto para cada presente

31 Ibid, p. 368. 
respectivo, [que] a la vez, mantiene su palabra dispuesta para todo futuro», ${ }^{32} \mathrm{y}$ es precisamente su actualidad como presente constituyente la que hace que se convierta en lenguaje. «La enigmática estructura temporal que se manifiesta aquí nos es conocida por el fenómeno de la fiesta». ${ }^{33}$ La misma fiesta reaparece toda vez que es celebrada y, al mismo tiempo, es distinta, y la estructura temporal del retornar diferente de lo idéntico termina por manifestarse común a todo ser en tanto histórico. La fiesta cuenta con dos aspectos convergentes en relación a la teoría fenomenológica de la conciencia del tiempo: 1) En toda celebración festiva, «el tiempo se convierte en el 'nunc stans' de un presente arrobador» ${ }^{34}$ por el cual recuerdo y presente son en ella una sola cosa. El presente constituyente (nunc stans) de Husserl se manifiesta en la forma de la temporalidad festiva y lo confirma el carácter temporalizante que Gadamer le atribuye. 2) La fiesta es una estructura que se comprende bastante mal si se parte de la experiencia temporal de la sucesión. Su retorno no significa que tiene un momento en el transcurso ordinario del tiempo,-sus referencias históricas son en verdad secundarias-, más bien indica que con su irrupción lo ordena y funda. Su esencia temporal como retornar se caracteriza por detener la conciencia del tiempo como sucesión de instantes de los que se dispone y motiva otro modo de conciencia no sucesiva, abierta al dativo de pre-dación temporal.

En continuidad con los análisis sobre el tiempo festivo, en un texto de madurez, Gadamer hace el distingo entre dos experiencias temporales fundamentales: el tiempo vacío y el tiempo lleno, que tienen aun más claramente su distinción convergente en Husserl. ${ }^{35}$ La primera refiere a la temporalidad ordinaria progresiva, que es el tiempo para algo, que se tiene o no, o sea, el tiempo vacío (leere Zeit) que podemos llenar y determina la conciencia de una sucesión temporal en el fluir de vivencias. Esta experiencia coincide con la distinción que hace Husserl respecto de la temporalización yoica en la que el yo introduce a través de las metas futuras y las adquisiciones pasadas de sus actos una temporalización propia. Pero, no es ésta, según Gadamer y Husserl, la experiencia fundamental del tiempo, pues allí «aun el tiempo no se experimenta como tiempo». ${ }^{36}$ En segundo lugar, está el tiempo lleno (erfüllte Zeit) o propio (Eigenzeit) que la celebración festiva pone de manifiesto. «Frente al tiempo vacío, que debe ser 'llenado', yo lo llamaría tiempo lleno, o también, tiempo

32 Gadamer, H.G., «Estética y Hermenéutica», $G W$ 8, p. 8.

33 Gadamer, H.G., GW 1, p. 128

34 Gadamer, H.G., «Sobre el carácter festivo del teatro», GW 8, p. 297.

35 Cf. Gadamer, H.G., «Sobre el tiempo vacío y lleno», GW 4. Tübingen: Mohr (Paul Siebeck), 1999, pp. 137-153. Gadamer lo escribió en 1969 en ocasión del 80 cumpleaños de Heidegger y lo consideraba «su respuesta a Ser y Tiempo».

36 Ibid., p. 132 
propio. Todo el mundo sabe que, cuando hay fiesta, ese momento, ese rato, están llenos de ella». ${ }^{37}$ Las fiestas son los momentos en los cuales el yo se da cuenta de su referencia al fundamento, es decir, adquiere conciencia de la pertenencia que da tiempo. Aquí la correspondencia se da con la temporalización no yoica que se produce de manera pasiva. El nunc stans se presenta bajo la forma de una discontinuidad temporal que «ofrece tiempo» ${ }^{38}$ y se impone a la conciencia del tiempo sucesivo en el modo de un detenerse desde el que ésta se ordena. De modo que la conciencia sucesiva se constituye desde lo extraño a ella (pero no ajeno) en tanto alcanza conciencia de la discontinuidad en el fluir ordinario del tiempo que es temporalizante. La conciencia diacrónica co-instituida de un «tiempo dado» es la conciencia de un horizonte donador, de una pre-dación de tiempo, instituida por la presencia que interpela al yo desde la pasividad afectante de su llamada.

Finalmente, el tiempo de fiesta es también tiempo propio, es decir, tiempo específico del organismo viviente y de la obra de arte. Gadamer continua las prometedoras investigaciones de Husserl sobre la vida en el terreno de la conciencia del tiempo, pues reconoce que, a través de la noción de vida, Husserl ha hecho su intento de ir más atrás de la actualidad de la conciencia y de alcanzar la intencionalidad anónima (no producida nominalmente por nadie) que constituye el horizonte de mundo que lo abarca todo. A través del tiempo propio, pone en evidencia la prototemporalidad de la vida más allá de la reflexividad que se alcanza en la conciencia del límite como discontinuidad en el que la identidad queda unida a la diferencia y que constituye el cuando de «cuando se comprende, se comprende de un modo diferente».

Estas convergencias dan prueba de la operatividad de la eficacia histórica que Gadamer recibe de los análisis tardíos sobre el tiempo y, a su vez, delinean las posibles ampliaciones que su hermenéutica puede ofrecer a la teoría fenomenológica de Husserl, indicando que en los textos «que ya no son meras palabras», hay también posibilidades para la investigación de las cosas mismas. 
FRANCISCO DÍEZ FISCHER es becario del Consejo Nacional de Investigaciones Científicas y Técnicas (CONICET) en Argentina. Actualmente es Profesor en la Facultad de Derecho de la Universidad Católica Argentina.

\section{Publicaciones recientes:}

«El juego agónico del arte. Un estudio estético-hermenéutico sobre la obra Zwei Skulturen für einen raum von Palermo de Gerhard Richter», en Fedro. Revista de estética y teoría de las artes. Núm. 8, marzo de 2009. ISSN 1697 - 8072, pp. 84-102.

«El extraño aquí y ahora de nuestras respuestas», en Revista de Humanidades, Universidad Andrés Bello, Chile, Vol. 21-22, Junio-Diciembre 2010, pp. 1-18.

Línea de investigación:

La noción de oído interior en la estética y la hermenéutica filosófica de Hans-Georg Gadamer.

Dirección electrónica: franciscodiezfischer@gmail.com 
